OAUTOR

Arthur Versiani Machado

Professor de História da Arte e História e Linguagem

do Cinema no CEFET - Ouro Preto. Especialista em

História Contemporânea.

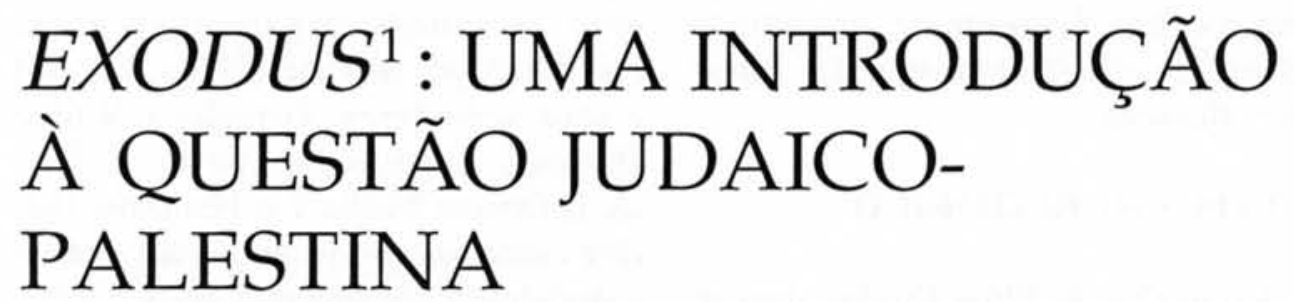

História ajuda a entender a causa palestina e a refletir sobre filme com pretensão universalista

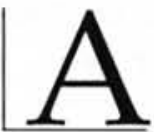

tualmente é muito comum entre os professores de História, Literatura e Filosofia o uso pedagógico de filmes comerciais, destes que são produzidos pelos grandes estúdios de cinema e distribuídos em todo o mundo. São exploradas as qualidades motivacionais e informativas deste meio, assim como a abertura que ele apresenta para a promoção do debate e da análise crítica.

Neste trabalho estará sendo discutido um filme relativamente antigo Exodus - uma superprodução dos anos 60 que ganhou recentemente uma nova edição em vídeo. $\mathrm{O}$ filme, uma narrativa ficcional, conta a história de uma jovem viúva americana que, querendo adotar uma criança sobrevivente ao holocausto nazista, acaba se envolvendo nos tumultuados episódios que marcaram a construção do Estado de Israel, na Palestina. Este é, sem dúvida, um tema que hoje deve ocupar posição destacada nos programas de ensino de História, face aos terríveis conflitos com os quais nos defrontamos.

$\mathrm{O}$ presente artigo analisa o filme numa perspectiva pedagógica, entendendo que, em sala de aula, é preciso fazer uma contextualização histórica prévia que permita uma compreensão integral do cenário sociocultural em que se desenrola o enredo. Além disso, é preciso que o professor, antes de elaborar sua estratégia de ensino, reconheça os elementos subjetivos que incidem sobre os discursos históricos, veiculados

1. Exodus - filme produzido nos EUA, em 1960, dirigido por Otto Preminger. Duração de $210 \mathrm{~min}$. 
pelo filme. Este artigo da um exemplo de reflexão histórica sobre um filme ficcional, ajudando o professor de História a encontrar formas de compreensão dos filmes comerciais de ambientação histórica para a construção de métodos de ensino que contribuam para o desenvolvimento de uma atitude crítica dos estudantes diante das narrativas fílmicas.

\section{CONTEXTO HISTÓRICO}

A temática do filme Exodus situa-se entre os anos 1946 e 1948 quando, terminada a Segunda Guerra Mundial, verificou-se um aumento considerável do fluxo migratório de judeus para a Palestina. Tal fato acirrou ainda mais a rivalidade entre judeus e palestinos, ambos originários daquela região do Oriente Médio, e que há muito debatem-se devido à crescente presença judaica na região.

Ainda que os principais fatores determinantes da questão judaico-palestina estejam situados no próprio século $\mathrm{XX}$, é necessário retroceder bem mais na história a fim de se compreender todo o processo que culminou na hostilidade que aflige a humanidade até os dias atuais.

Os hebreus (ancestrais dos judeus) ocuparam a Palestina no segundo milênio antes de Cristo e construíram ali uma civilização que seria imortalizada pelos escritos sagrados de três das mais influentes religiões de todos os tempos: o cristianismo, o islamismo e o judaísmo. Como toda grande civilização, a hebraica conheceria, após o apogeu, seu momento de decadência. A Terra de Israel dos hebreus foi ocupada seguidamente por assírios, babilônios, persas, gregos e ro- manos. No ano 70 da era cristã, estes últimos expulsaram de lá os judeus, que se dispersaram por todo o Império Romano, na primeira grande diáspora (dispersão) a que este povo foi submetido.

A Palestina foi ocupada pelos árabes a partir do ano 636 da era cristã, resultado da grande expansão islâmica provocada por Maomé $(570-632 \mathrm{dC})$ e seus seguidores. O poder islâmico chegou a atingir todo o Norte da África, o Oriente Médio e a Península Ibérica européia. Houve então um efetivo e duradouro povoamento árabe na $\mathrm{Pa}$ lestina, mas o domínio político das lideranças árabes naquela região deixaria de prevalecer depois de um certo tempo. Após as cruzadas, assistiu-se a um curto período de dominação cristã sobre a Palestina (1229-1244). Depois chegaram os mamelucos (1291), vindos do Egito, que impuseram um longo domínio político sobre a região.

Finalmente, os turcos

otomanos, que também

professavam a religião islamita, passaram a controlar a Palestina, de forma mais consistente, do século XV até o final da Primeira Guerra Mundial.

Nessa guerra, a Turquia, que se aliara à Alemanha e à Áustria, foi derrotada e o seu vasto império no Oriente Médio desmembrado. Surgiram então os Estados da Transjordânia (atual Jordânia), Síria, Líbano, Iraque, Egito, 
Pérsia (atual Irã) e Palestina. Estes Estados seriam divididos e tutelados pelas potências européias vencedoras da Primeira Guerra - França e Inglaterra - interessadas sobretudo nas reservas de petróleo e no controle das rotas comerciais da região (leia-se: Canal de Suez $^{2}$ ). Em 1922, a Liga das Nações estabeleceu oficialmente que o controle político sobre a Palestina, região tão inóspita quanto estratégica, caberia à poderosa Inglaterra.

Paralelamente a estes acontecimentos, ocorrem fatos decisivos para o futuro da Palestina na distante Rússia e no Leste Europeu. A partir de meados do século $\mathrm{XIX}$, as perseguições aos judeus se intensificaram nestas regiões, seja pela ação do governo czarista russo, que incentivava o racismo, seja pelo desenvolvimento de uma mentalidade nacionalista no Leste Europeu, que estigmatizava o povo judeu na disputa pelos postos de trabalho. Esta nova onda de anti-semitismo vai fortalecer o sionismo (de Sion, nome de uma colina situada em Jerusalém), movimento internacional que visava à redenção do povo judeu através da edificação de um Estado judaico na Palestina.

\section{SIONISMO}

O primeiro congresso sionista foi organizado pelo jornalista húngaro Theodor Herzl (1860 - 1904), em 1897, na Suíça. A partir de então, muitas ações se desenvolveram em diversas frentes. Enquanto alguns sionistas disseminavam suas idéias em jornais e livros, outros implementavam ações políticas de convencimento das autoridades européias sobre a necessidade de se criar um Estado judeu. Foram promovidas também campanhas de arrecadação de fundos junto aos judeus de todo o mundo para comprar terras na Palestina e financiar a ocupação daquela região por colonos de origem judaica. $\mathrm{O}$ acirramento do anti-semitismo na Europa nas primeiras décadas do século XX, além das ações efetivas da Organização Sionista Mundial levaram a uma forte tendência migratória em direção à Palestina, o que ocasionou a imediata reação da população árabe ali estabelecida.

Em 1917, através da Declaração Balfour, a Inglaterra se compromete com o "estabelecimento de um lar nacional para o povo judeu", ponderando que "não se fará nada que possa acarretar prejuízos aos direitos civis ou religiosos das comunidades não judias da Palestina".

Mais que uma postura conciliatória, a Declaração Balfour vai inaugurar uma política britânica para a Palestina, marcada pela hesitação e pela ambigüidade.

As decisões das autoridades inglesas convergem ora para os interesses sionistas, ora para os interesses dos árabes

2. Canal de Suez é a ligação, através de um canal, entre os mares Mediterrâneo e Vermelho. A sua construção foi iniciada em 1859 e durou dez anos. O projeto de construção foi coordenado pelo engenheiro francês Ferdinand de Lesseps e teve como acionistas França e Reino Unido. Para a sua inauguraçâo, em 17/11/1869, Giuseppe Verdi compōe a ópera Aída. O Canal de Suez foi durante longo período motivo de disputas e guerras. (N. Ed.) 
palestinos, numa típica posição de quem tenta, a todo custo, se equilibrar na discórdia para eternizar-se no poder.

Diante da reação árabe à crescente chegada de judeus, os ingleses editam, em 1922, o primeiro Livro Branco, instrumento jurídico que deveria limitar a imigração judaica. Todavia a lei tornouse letra morta e não conseguiu impedir a entrada de um número cada vez maior de judeus na Palestina.

Com a ascensão de Hitler ao poder na Alemanha, em 1933, o fluxo migratório para a Palestina aumentou ainda mais devido à perseguicão que os nazistas empreenderam sobre os judeus alemães. Entre 1933 e 1938 duzentos mil novos colonos judeus chegaram à Palestina. A reação árabe, desta feita, foi mais intensa. Em 1936 organizaram greves de grande porte e promoveram intensos combates armados. Algumas lideranças árabes chegaram a buscar apoio em Hitler, maior inimigo de seus inimigos - os ingleses e os judeus.

Pressionada pela reação árabe, a Inglaterra é levada a editar, em 1939, o segundo Livro Branco, mais rigoroso e efetivo contra o povoamento judeu da Palestina. Continua a imigração clandestina, mas o duro controle inglês faz com que os judeus se voltem contra as autoridades britânicas da Palestina de forma cada vez mais violenta.

As mais antigas e importantes organizações judaicas estabelecidas na $\mathrm{Pa}$ lestina eram o Hagannah, instituição militar que fazia a proteção da comunidade, e a Agência Judaica, órgão executivo que organizava a administração das colônias em colaboração com as autoridades britânicas. As duas instituições eram aceitas pelos ingleses.
Com as restrições de imigração impostas pela Inglaterra, o movimento sionista

ramificou-se. Surgiram novos grupos paramilitares extremistas, como o Irgun e o Stern que, no final da Segunda Guerra, realizaram atos de sabotagem e terrorismo contra a administração britânica e contra os povoamentos árabes.

O mais impactante ataque terrorista destes grupos foi em 1946, quando uma bomba explodiu no King David Hotel, matando 91 pessoas, a maioria delas funcionários da administração inglesa.

Com o fim da guerra, a opinião pública mundial passa a apoiar irrestritamente a causa judaica, sensibilizada com o sofrimento dos judeus sob o regime nazista. O mundo pretensamente civilizado da Europa criou a barbárie e deveria expiar suas culpas compensando os judeus pelos crimes contra eles cometidos. Por outro lado, os governantes árabes dos países vizinhos à Palestina, temendo o avanço dos interesses ocidentais sobre o Oriente Médio, criaram, em 1945, a Liga Árabe e se posicionaram claramente contra o sionismo.

A Inglaterra, percebendo o acirramento das posições e diante da impossibilidade de resolver o impasse, transfere a responsabilidade do problema para a recém fundada Organização das Nações Unidas. Em novembro de 1947, a ONU decide pela divisão da Palestina 
em dois Estados - um árabe e outro judeu. Os árabes palestinos não concordaram com esta decisão por entenderem que a terra lhes pertencia e que a ONU não tinha legitimidade para arbitrar esta questão.

No dia 14 de maio de 1948, a Inglaterra abandona a Palestina e o Estado de Israel é proclamado. Imediatamente os países árabes vizinhos declaram guerra ao novo país. Melhor armados e treinados, os israelenses vencem o conflito com relativa facilidade, aproveitando-se para expandir ainda mais seus territórios e tomar $70 \%$ da área que, pela partilha da $\mathrm{ONU}$, deveria pertencer à Palestina árabe. Os outros $30 \%$ - as regiões da Cisjordânia e da faixa de Gaza - seriam anexados, ao final do conflito, pela Jordânia e pelo Egito, respectivamente. Resultado: a Palestina árabe deixou de existir antes mesmo de ser proclamada. Ao povo Palestino, coube uma difícil escolha. Continuar vivendo em Israel, como indivíduos de quinta categoria, ou mudar-se para os insalubres campos de refugiados palestinos erigidos nos países vizinhos.

Em 1948, resolve-se a Questão Judaica e coloca-se a Questão Palestina. A fundação do Estado de Israel foi apenas o primeiro ato de uma peça macabra que ainda viria a encenar muitos outros episódios de guerras, sofrimento e terror.

\section{ANÁLISE DO FILME}

A história de amor contada pelo filme parece ser apenas um pretexto usado pelos autores para abordar a questão da criação do Estado de Israel. São apresentados no filme muitos elementos importantes para a compreensão deste acontecimento tão decisivo para a história contemporânea.

$\mathrm{Na}$ primeira parte da fita, quando a ação ainda se desenvolve na Ilha de Chipre, são apresentados os problemas decorrentes da perseguição nazista, o périplo doloroso do povo sem terra, as dificuldades colocadas pelas autoridades inglesas para a entrada de judeus na Palestina, as péssimas condições dos campos de refugiados, a firmeza dos judeus exilados, dispostos a morrer por seu ideal sionista. Nesta fase do filme há grande verossimilhança entre os fatos ficcionais por ele apresentados e os fatos históricos.

Outra informação interessante colocada pelo filme diz respeito às formas de integração dos imigrantes recém-chegados à Palestina. Boa parte deles era imediatamente levada às propriedades coletivas, denominadas kibutzim. Ali, os resultados da produção eram revertidos sem distinção para todos os membros da comunidade, as decisões eram tomadas em Assembléia Geral, as tarefas sociais e militares eram divididas igualmente $\mathrm{e}$ assumidas com fervor patriótico. Esta estrutura socioeconômica ousada e inovadora deriva em boa medida das propostas socialistas vigentes na Europa, já que os judeus representavam parte significativa do movimento socialista europeu.

Mas, na Palestina judia, a igualdade socialista no campo era relativizada. 
Apenas se pressupunha a igualdade entre os iguais. Ou seja, não se concebia a participação de árabes nos kibutzim ou em qualquer outra forma de organização social judaica. $\mathrm{O}$ mundo árabe era um mundo à parte, absolutamente desvinculado da utopia sionista. E o filme Exodus, que claramente assume o ponto de vista dos colonizadores judeus, reafirma tal postura de exclusão.

A ocupação da Palestina pelos judeus, feita de forma excludente e sectária gerou, como era de se esperar, muita insatisfação entre os árabes. Uma insatisfação crescente, na exata medida do aumento do fluxo migratório. No entanto, o filme desconsidera totalmente a questão populacional, as limitações de território e de mercado de trabalho daquele país de geografia tão desfavorável. A revolta dos nativos não é justificada pelo filme. Pelo contrário, a convivência pacífica e o respeito mútuo entre árabes e judeus são enfatizados ao longo de todo o filme e o único personagem palestino apresentado com simpatia é Taha, aquele que, tal como seu pai, teria sido tolerante e amigo dos judeus.

Normalmente, quando

Holywood se debruça sobre a questão judaico-palestina, o enfoque adotado é extremamente maniqueísta. Os árabes são representados como pessoas brutas e frias, terroristas sanguinários, fanáticos, irracionais.
Por seu turno, os personagens judeus costumam encarnar a justiça, a razão, a abnegação e o heroísmo. Há uma nítida distinção entre o espaço do bem e o espaço do mal.

Os autores do filme Exodus tentam romper em alguma medida com este maniqueísmo exagerado, apresentando personagens árabes muito diferentes das caricaturas usuais e não omitindo determinadas atitudes dos judeus que poderiam ser, aos olhos do espectador, extremamente questionáveis. Apesar disso, é indisfarçável a parcialidade assumida pela obra na defesa da causa sionista.

Uma das qualidades do filme está no fato de que ele assume atos terroristas praticados por judeus contra os ingleses. E mais, mostra a colaboração entre as facções moderadas (Hagannah) e os grupos radicais (Irgun). Isso atenta contra o discurso típico dos judeus, que sempre recusam o terrorismo como prática política. De certa forma, o radicalismo é condenado pelo filme, mas o enfoque adotado é extremamente indulgente com os terroristas judeus. $\mathrm{O}$ tio de Ari Ben Canaan, personagem principal do filme, chefe do Irgun, está equivocado por pregar a violência, mas é perdoado porque possui o espírito nobre de bom combatente e faz parte da melhor estirpe judia. $\mathrm{O}$ ímpeto agressivo do garoto Dov é apresentado como um destempero juvenil, plenamente justificável em função das misérias que viveu. No final do filme, o jovem terrorista ganha ares de herói.

Mas se é indulgente com os radicais judeus que mataram 91 pessoas no King David Hotel, o filme é implacável com 
os árabes quando mostram a sua reação à decisão da $\mathrm{ONU}$ de dividir a Palestina em dois Estados. Árabes sem rosto enforcam cruelmente Taha, o amigo palestino de Ari Ben, ameaçam as criancinhas das colônias judaicas e matam covardemente a jovem e inocente Karen.

Nas suas cenas finais, o filme deixa bastante claro que a luta contra os ingleses e a batalha diplomática na ONU, que resultaram na criação do estado de Israel, foi apenas o começo de uma longa jornada. A abnegação e combatividade dos judeus ainda teria que se haver com a crueldade e a irracionalidade dos árabes, num longo e extenuante conflito entre civilização e barbárie.

\section{HISTÓRIA E FICÇÃO}

O trabalho com filmes comerciais de cunho histórico pode ser extremamente útil ao aprendizado de história, contribuindo para o desenvolvimento da capacidade de análise, compreensão e crítica dos alunos. No entanto, para que o resultado seja satisfatório, é necessário que o professor saiba reconhecer todos os elementos do filme que evocam situações históricas importantes, contextualizando-os com precisão. Torna-se necessário também o conhecimento de algumas das condições de produção do filme, tais como o ano e o país de origem, as eventuais filiações políticas de produtores e diretores e, em alguns casos, as fontes financiadoras do filme.

Os filmes históricos comerciais não foram produzidos para serem utilizados em sala de aula. Eles não têm, ne- cessariamente, compromisso com a verdade histórica e com o rigor científico, além de não se preocuparem com as questões de caráter didático-pedagógico. Concebidos, na sua maioria, como mero entretenimento, os filmes históricos comerciais costumam falsear a realidade, transmitir concepções estereotipadas dos acontecimentos, reforçar uma imagem heróica das personagens, apresentar erros históricos crassos, sucumbir ao apelo das ideologias, entre outras deturpações históricas graves.

$\mathrm{O}$ mais grave é que, entre os muitos malefícios provenientes do poder desmesurado dos meios de comunicação de massa, está o de criar o consenso em torno das representações mentais, nas mais variadas esferas da vida humana.

A modernidade fabrica e difunde seus mitos através da indústria cultural. $\mathrm{O}$ estereótipo do árabe fanático e sanguinário e, por oposição, a imagem do judeu como vítima indefesa são exemplos desta padronização das representações mentais.

Além disso, como afirma Jacques Aumont: "para tornar seu trabalho e sua função naturais, o filme de ficção tende, com freqüência, a escolher como tema as épocas históricas e os pontos de atualidade a respeito dos quais já existe um 'discurso comum'. Assim, fin- 
ge submeter-se à realidade, enquanto só tende a tornar sua ficção verossímel. Aliás, é por aí que ele se transforma em veículo para a ideologia"

Não há dúvidas de que o cinema, não apenas o de ficção, como também o filme histórico, muitas vezes reforça esta estandardização ou padronização do conhecimento propiciada pelos meios de comunicação de massas. Padrões de comportamento, valores, idéias, são apontados como verdades universais, princípios indiscutíveis. Sucumbir a tal poder representa a negação da crítica.

O desmascaramento da pretensão universalista da indústria cultural passa pelo trato pedagógico de suas men-

Resumo: $\mathrm{O}$ artigo discute o tratamento dado pelo filme Exodus, de Otto Preminger, ao episódio da criação do Estado de Israel, acontecimento fundamental para o entendimento da realidade atual. A contextualização histórica do filme, bem como a caracterização do ponto de vista adotado pelos seus autores apresentam-se como etapas imprescindíveis para a análise crítica de professores e alunos de História, diante de um meio de ensino cada vez mais utilizado em sala de aula: o filme histórico comercial.

Palavras-chave: Questão Palestina, Estado de Israel, Exodus, História, filmes históricos sagens. O filme histórico comercial pode se tornar um instrumento mais do que adequado para o exercício da crítica, desde que o professor o utilize de tal modo que os alunos venham a conceber o discurso ali difundido como uma das leituras possíveis da história, entre outras tantas. $\mathrm{O}$ aluno, através de uma metodologia bem articulada, pode ser levado a identificar a interpretação do autor e a avaliá-la, a partir de seus critérios. Mais do que isso, na medida em que reconhece e analisa uma opinião, pode, com muita facilidade, ser incitado a adotar uma posição própria sobre os fenômenos históricos ali trabalhados.

(Exodus: an introduction to the JudeoPalestinian matter)

Abstract:The article discusses the treatment given by Otto Preminger's movie Exodus to the episode of the creation of the State of Israel, a happening that was fundamental for one to understand the current reality. The movie's historical contextualization, and the characterization of the point of view adopted by the authors are stages of the utmost importance for critical analyses by teachers and students of History, using an educational medium that is increasingly common in the classroom: the commercial historical movie.

Key words: Palestinian Matter, State of Israel, Exodus, History, historical movies

3. AUMONT, Jacques. A imagem. Campinas/São Paulo: Papirus, 1995. p. 106.

Outras importantes fontes são:

BRENER, Jaime. Ferida Aberta: o Oriente Médio e a nova ordem mundial. São Paulo: Atual, 1993.

HOBSBAWN, Eric J. A era dos impérios. Rio de Janeiro: Paz e Terra, 1992.

MACHADO, Arthur Versiani. A seleção de meios de ensino: o caso dos filmes históricos comerciais. Anais do

V Encontro Nacional Perspectivas do Ensino de História. Ouro Preto: UFOP, no prelo.

SALEM, Helena. O que é a Questão Palestina. São Paulo: Brasiliense, 1990. 